\title{
Longitudinal static stability analysis with wing swept angle variation of UAV flying wing surveillance adelaar 2 use software XFLR 5
}

\author{
Prytha Virgiawan Lesalli*, M. Ardi Cahyono \\ Departemen Teknik Dirgantara, Sekolah Tinggi Teknologi Adisutjipto \\ Email Korespondensi : *lesalliprytha@gmail.com
}

\begin{abstract}
Aircraft stability is very important for calculated in aircraft design, specially for UAV which will be used for air surveillance. The purpose of aircraft stability analysis to find aircraft stability characteristic. Aircraft static stability can be analyzed by XFLR 5 Software which is can calculate characteristic of aircraft static stability, show visual, graph, and simulation of aircraft stability. Adelaar 2 is UAV with flying wing configuration and will be analyzed use software XFLR 5 with the input of aircraft mass with the centre of gravity will be located in $5 \%$ of mean aerodynamic chord in front of neutral point and aircraft geometry types of airfoil in chord root, tip, span, winglet geometry and wing swept. With the result that Adelaar 2 is qualify for longitudinal static stability after the author analyze use XFLR5 with the parameter and obtained character of stability for $22,5^{\circ}, 25^{\circ}, 27,5^{\circ}$, and $30^{\circ}$ wing swept angle.
\end{abstract}

Keywords: Aircraft Stability, UAV, XFLR

\section{Pendahuluan}

Seiring dengan berkembangnya permintaan akan pemetaan, diperlukan berbagai macam metode pemetaan. Dengan memanfaatkan kemajuan teknologi kamera udara, film dan pesawat, maka pekerjaan pemetaan dapat dilakukan dengan waktu yang relatif cepat dan akurasi tinggi [3]. Salah satu alternatif pemetaan adalah menggunakan UAV (Unmanned Aerial Vehicle) yang mengambil citra dari udara. UAV adalah perangkat yang diterbangkan di udara tanpa adanya penerbang di dalamnya atau yang sering dikenal dengan drone yang dikendalikan oleh programmed autonomous flight atau remote pilot [1].

Konfigurasi UAV yang sering digunakan untuk pemetaan udaran adalah fixed wing dan multi rotor. Multi rotor memiliki kestabilan yang lebih baik dibanding dengan fixed wing, namun fixed wing umumnya lebih hemat daya dibanding multi rotor karena jumlah penggerak fixed wing yang lebih sedikit dibanding dengan multi rotor[4].

Dalam penerapan definisi stabilitas statik adalah kecenderungan untuk melawan gangguan diukur dengan menggunakan sifat gaya dan momen pesawat terbang yang timbul karena pesawat mendapat gangguan dari keadaan terbang steady, dimana center of gravity menjadi titik pusatnya. Pesawat dikatakan stabil apabila pesawat kembali ke posisi awal setelah diberi gangguan, dengan memperhatikan parameter $C_{m a}<0[5]$. 
Adelaar 2 merupakan UAV dengan konfigurasi fixed wign flying wing yang dirancang dan dimanufaktur oleh tim Unit Kegiatam Mahasiswa Aeromodelling dan mahasiswa Sekolah Tinggi Teknologi Adisutjipto Yogyakarta, misi terbang pesawat ini berupa pemotretan di udara atau surveillance, dengan pendorong single engine pusher berupa brushless motor. Oleh karena itu perlu nya optimasi terhadap kestabilan pesawat ketika terbang terutama dalam matra longitudinal.

\section{Metodologi Penelitian}

UAV didesain pada software XFLR 5 dengan memasukan beberapa parameter wing dan winglet seperti pada Gambar 1.


Gambar 1. Parameter Desain Sayap

Variabel tersebut adalah bentang sayap (b), panjang chord root $\left(\mathrm{C}_{\mathrm{r}}\right)$, Chord tip $\left(\mathrm{C}_{\mathrm{t}}\right)$, jenis airfoil, massa pesawat $(\mathrm{m})$, letak pusat massa pesawat $\left(\mathrm{X}_{\mathrm{Cg}}\right)$, jarak leading edge $\mathrm{C}_{\mathrm{r}}$ dengan leading edge $\mathrm{C}_{\mathrm{t}}$ terhadap sumbu $\mathrm{X}\left(\mathrm{X}_{\mathrm{Ct}}\right)$ seperti yang ditunjukan pada Tabel 1 , Variabel $\mathrm{X}_{\mathrm{Ct}}$ dipengaruhi oleh variasi sudut swept di $0,25 \operatorname{chord}(\varphi)$ sebesar $22,5^{\circ}, 25^{\circ}, 27,5^{\circ}$ dan $30^{\circ}$ dengan sudut serang $(\alpha)-20^{\circ}$ hingga $20^{\circ}$.

Tabel 1. Variabel Input Geometri Sayap

\begin{tabular}{ccc}
\hline$b(m)$ & $C_{r}(m)$ & $C_{t}(m)$ \\
\hline 1,8 & 0,435 & 0,26 \\
\hline
\end{tabular}

Beberapa variabel konstan meskipun dilakukan perubahan sudut swept sayap[7], seperti tapper ratio $(\lambda)$ yang didapatkan dari persamaan 1.

$$
\lambda=\frac{c r}{c t}
$$

Variabel mean aerodynamic chord (Mac) didapatkan melalui persamaan 2.

$$
\text { Mac }=\frac{2}{3} \times \frac{1+\lambda+\lambda^{2}}{1+\lambda} \times C r
$$

Jarak neutral point dengan $\mathrm{C}_{\mathrm{r}}$ terhadap sumbu $\mathrm{Y}(\mathrm{Y})$ didapatkan dari persamaan 3.

$$
Y=\frac{b}{2} \times \frac{C r-M a c}{C r-c t}
$$

Sehingga didapatkan variabel seperti pada Tabel 2.

Tabel 2. Variabel $\lambda$, Y dan Mac

\begin{tabular}{ccc}
\hline$\lambda$ & $\mathrm{Y}(\mathrm{m})$ & Mac $(\mathrm{m})$ \\
\hline 0,597701 & 0,41223 & 0,354844 \\
\hline
\end{tabular}

Namun, dikarenakan perubahan variabel sudut swept 0,25 chord $(\varphi)$ maka mempengaruhi variabel lain seperti, $\mathrm{X}_{\mathrm{Np}}, \mathrm{X}_{\mathrm{Cg}}$ dan $\mathrm{X}_{\mathrm{Ct}}$. Dengan persamaan 4 maka didapatkan letak neutral point dari leading edge chord root terhadap sumbu $\mathrm{X}\left(\mathrm{X}_{\mathrm{Np}}\right)$.

$$
X N p=\frac{C r}{4}+\frac{b(1+2 \lambda)}{6(1+\lambda)} \times \tan (\varphi)
$$


Dengan persamaan 5 maka didapatkan letak pusat massa dari leading edge chord root terhadap sumbu $\mathrm{X}$ $(\mathrm{Cg})$.

$$
X C g=X N p-0.05 \times M a c
$$

Dengan persamaan 6 maka didapatkan letak leading edge chord tip dari leading edge chord root terhadap sumbu $\mathrm{X}(\mathrm{Cg})$.

$$
X C t=\tan (\varphi) \times \frac{2 b-C r-C t}{4}
$$

Sehingga didapatkan data $\mathrm{X}_{\mathrm{Np}}, \mathrm{X}_{\mathrm{Cg}}$ dan $\mathrm{X}_{\mathrm{Ct}}$ seperti pada Tabel 3.

Tabel 3. Variabel $X_{\mathrm{Np}}, X_{\mathrm{Cg}}$ dan $X_{\mathrm{Ct}}$

\begin{tabular}{lcccc}
\hline & $\varphi\left({ }^{\circ}\right)$ & $\mathrm{X}_{\mathrm{Np}}(\mathrm{m})$ & $\mathrm{X}_{\mathrm{Cg}}(\mathrm{m})$ & $\mathrm{X}_{\mathrm{Ct}}(\mathrm{m})$ \\
\hline Wing 1 & 22,5 & 0,279501 & 0,261759 & 0,416542 \\
Wing 2 & 25 & 0,300976 & 0,283234 & 0,463427 \\
Wing 3 & 27,5 & 0,323343 & 0,305601 & 0,51226 \\
Wing 4 & 30 & 0,346751 & 0,329009 & 0,563365 \\
\hline
\end{tabular}

Massa pesawat (m) ditentukan dari variasi massa dan wing span (b) pesawat pembanding seperti yang ditunjukan pada Tabel 4. [6].

Tabel 4. Data pesawat pembanding

\begin{tabular}{cccc}
\hline & Wing Span $(\mathrm{m})$ & Massa $(\mathrm{kg})$ & Kecepatan $(\mathrm{m} / \mathrm{s})$ \\
\hline Parrot & 1,15 & 0,7496432 & 22,2 \\
X6 & 1,5 & 1,9992864 & 11,1 \\
X8 & 2,12 & 3,4987768 & 22,2 \\
Earth Line & 2,6 & 4,9982671 & 22,2 \\
Big Drone & 3,05 & 5,4980632 & 22,2 \\
\hline
\end{tabular}

Dari data Tabel 3 didapatkan regresi massa pesawat terhadap wing span (b) yang ditetapakan adalah 1,8 $\mathrm{m}$, dan didapatkan persamaan (7) sehingga diperoleh massa pesawat sebesar $1.486 \mathrm{Kg}$

$$
m=0.3857 \times(b)+0.7922
$$

Airfoil yang digunakan adalah MH-60 untuk sayap pesawat dan NACA-0009 untuk winglet. Simulasi dilakukan menggunakan software XFLR 5, analisis meliputi gradien koefisien momen terhadap sudut serang pesawat $\left(C_{m a}\right)$, sehingga pesawat dikatakan memiliki kestabilan statik matra longitudinal apabila gradien momen pitch harus memiliki gradien negatif. $C_{m a}<0$, dan karakteristik kestabilan statik longitudinal berdasarkan gradien $C_{m a}$ [5].

\section{Hasil dan Pembahasan}

Proses analisis dimulai dengan memasukan input jenis airfoil yang akan digunakan kedalam XFoil design, dimana airfoil yang digunakan adalah MH-60 dan NACA-009 dengan memasukan kedalam multi threaded batch analysis untuk mengetahui karakter airfoil dari Reynold number 200.000 hingga 1.00 .000 seperti pada Gambar 2. 




Gambar 2. XFoil design and multi threaded batch analysis

Proses selanjutnya adalah plane design, dimana memasukan desain sayap pesawat dengan parameter geometri seperti yang ditunjukan pada Gambar 3.

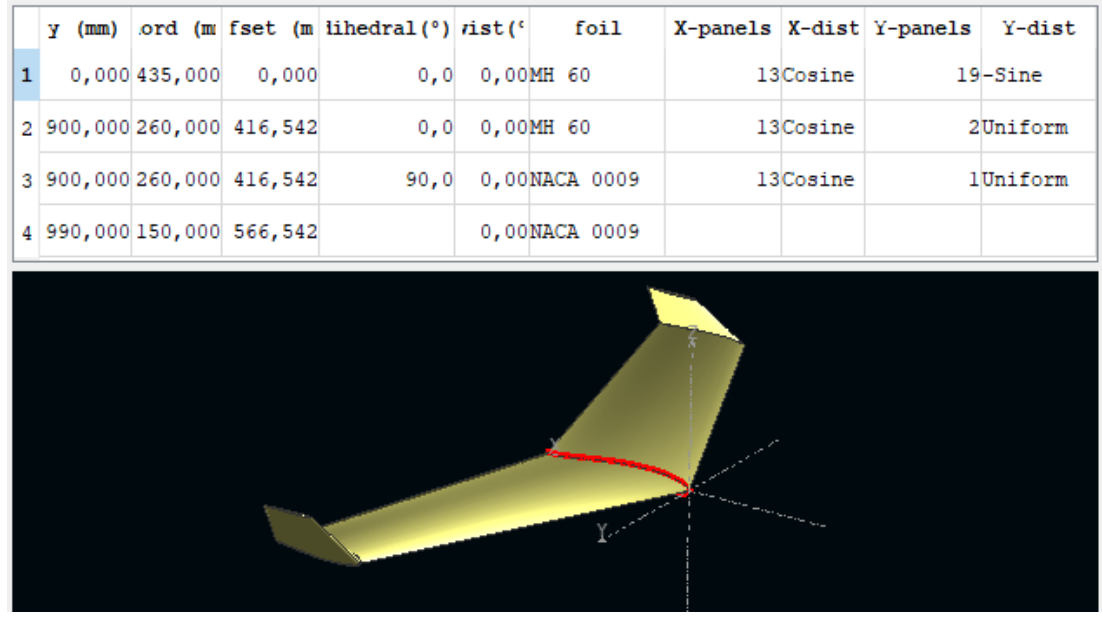

Gambar 3. Geometri Sayap

Massa pesawat dan lokasi Cg didefiniskan kedalam parameter plane inertia additional point masses dengan massa 1,486 Kg dan pusat massa terletak pada $261,759 \mathrm{~mm}$ dari chord root leading edge seperti pada Gambar 4.

\begin{tabular}{|c|c|c|c|c|c|}
\hline & iss ( $\mathrm{k}$ c & $x \quad(m m)$ & Y $(\mathrm{mm})$ & $z \quad(m m)$ & Descriptiol \\
\hline 1 & 1,486 & 261,759 & 0,000 & 0,000 & Total Mass \\
\hline 2 & 0,000 & 0,000 & 0,000 & 0,000 & \\
\hline$<$ & & & & & $>$ \\
\hline
\end{tabular}

\section{Gambar 4. Additional Point Masses}

Analisis didefinisikan kedalam fixed speed and ring vortex analysis, dengan kecepatan konstan $20 \mathrm{~m} / \mathrm{s}$, dimana nilai kecepatan diambil dari data range kecepatan pesawat pembanding pada Tabel 4 dan 
analysis setting mengatur sudut serang yang akan dihadapi pesawat ketika terbang dengan asumsi $-20^{\circ}$ hingga $20^{\circ}$.seperti pada Gambar 5.

\begin{tabular}{|c|c|c|c|c|c|c|}
\hline Polar Type & Analysis & Inertia & Ref. dimensions & Aero data & Extra drag & \\
\hline \multicolumn{3}{|c|}{ (C) Type 1 (Fixed Speed) } & \multicolumn{2}{|c|}{ Free Stream Speed = } & 20,00 & $\mathrm{~m} / \mathrm{s}$ \\
\hline \multicolumn{3}{|c|}{ Type 2 (Fixed Lift) } & & $\alpha=$ & 0,00 & 。 \\
\hline \multicolumn{3}{|c|}{ Type 4 (Fixed aoa) } & & $\beta=$ & 0,00 & 0 \\
\hline
\end{tabular}

Gambar 5. Analysis Definitions and Seting.

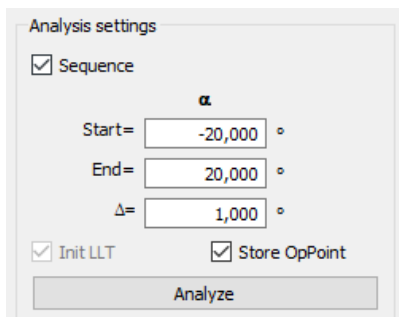

Dari hasil analisis didapatkan koefisien momen pesawat terhadap sudut serang yang variatif pada tiap sudut serang dan sudut swept, didapatkan hasil seperti pada Tabel 5 dan Gambar 6.

Tabel 5. Hasil Analisis $\mathrm{C}_{\mathrm{m}}$

\begin{tabular}{|c|c|c|c|c|}
\hline$\alpha$ & $\mathrm{C}_{\mathrm{m}}$ Wing 1 & $\mathrm{C}_{\mathrm{m}}$ Wing 2 & $\mathrm{C}_{\mathrm{m}}$ Wing 3 & $\mathrm{C}_{\mathrm{m}}$ Wing 4 \\
\hline-12 & & & & 0,049637 \\
\hline-11 & 0,040984 & 0,043551 & 0,045259 & 0,047198 \\
\hline-10 & 0,039118 & 0,040264 & 0,042301 & 0,044099 \\
\hline-9 & 0,035317 & 0,03604 & 0,036904 & 0,038171 \\
\hline-8 & 0,030943 & 0,031909 & 0,03303 & 0,034299 \\
\hline-7 & 0,02783 & 0,028672 & 0,029642 & 0,030736 \\
\hline-6 & 0,024673 & 0,025389 & 0,026212 & 0,02714 \\
\hline-5 & 0,021504 & 0,022095 & 0,022772 & 0,023533 \\
\hline-4 & 0,018301 & 0,018769 & 0,019302 & 0,019898 \\
\hline-3 & 0,015062 & 0,015407 & 0,015794 & 0,016222 \\
\hline-2 & 0,011791 & 0,012013 & 0,012256 & 0,012518 \\
\hline-1 & 0,008487 & 0,008586 & 0,008684 & 0,00878 \\
\hline 0 & 0,005154 & 0,005129 & 0,005082 & 0,005013 \\
\hline 1 & 0,001792 & 0,001645 & 0,001454 & 0,001219 \\
\hline 2 & $-0,001592$ & $-0,001862$ & $-0,002196$ & $-0,002596$ \\
\hline 3 & $-0,004994$ & $-0,005386$ & $-0,005863$ & $-0,006427$ \\
\hline 4 & $-0,008411$ & $-0,008924$ & $-0,009543$ & $-0,010271$ \\
\hline 5 & $-0,011838$ & $-0,012471$ & $-0,013232$ & $-0,014121$ \\
\hline 6 & $-0,015272$ & $-0,016024$ & $-0,016925$ & $-0,017975$ \\
\hline 7 & $-0,018709$ & $-0,019579$ & $-0,020619$ & $-0,021827$ \\
\hline 8 & $-0,022145$ & $-0,023132$ & $-0,024309$ & $-0,025675$ \\
\hline 9 & $-0,025577$ & $-0,026679$ & $-0,027991$ & $-0,029513$ \\
\hline 10 & $-0,029$ & $-0,030216$ & $-0,031663$ & $-0,033338$ \\
\hline 11 & $-0,032413$ & $-0,033741$ & $-0,03532$ & $-0,037147$ \\
\hline 12 & $-0,035811$ & $-0,037251$ & $-0,03896$ & $-0,040936$ \\
\hline 13 & $-0,039188$ & $-0,040738$ & $-0,042576$ & $-0,0447$ \\
\hline 14 & $-0,042544$ & $-0,044199$ & $-0,046163$ & $-0,048432$ \\
\hline 15 & $-0,045905$ & $-0,047661$ & $-0,049738$ & $-0,05214$ \\
\hline 16 & & & $-0,053348$ & $-0,05589$ \\
\hline
\end{tabular}




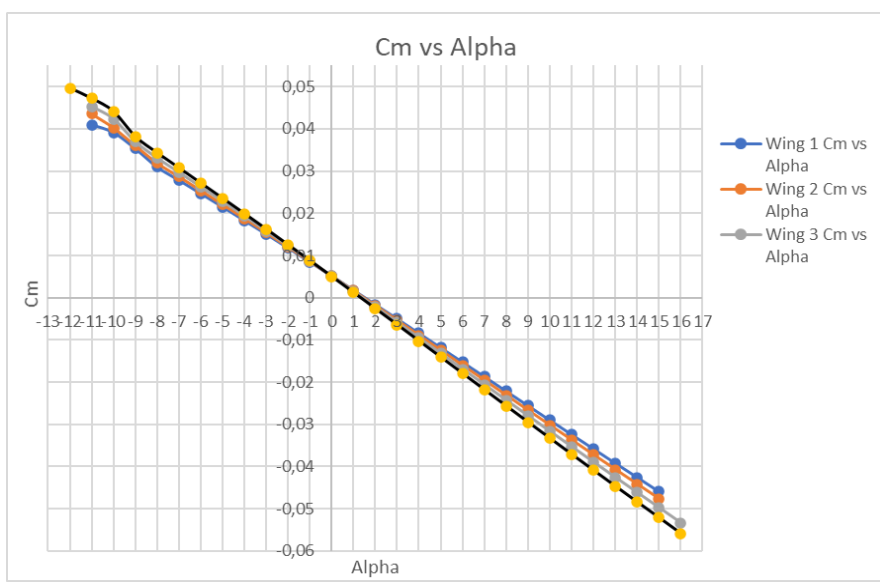

Gambar 6. Gradien $C_{m}$ vs $\alpha$.

Regresi dari $\mathrm{C}_{\mathrm{m}}$ vs $\alpha$ dari data tabel 5 didapatkan hasil seperti pada gambar 7.
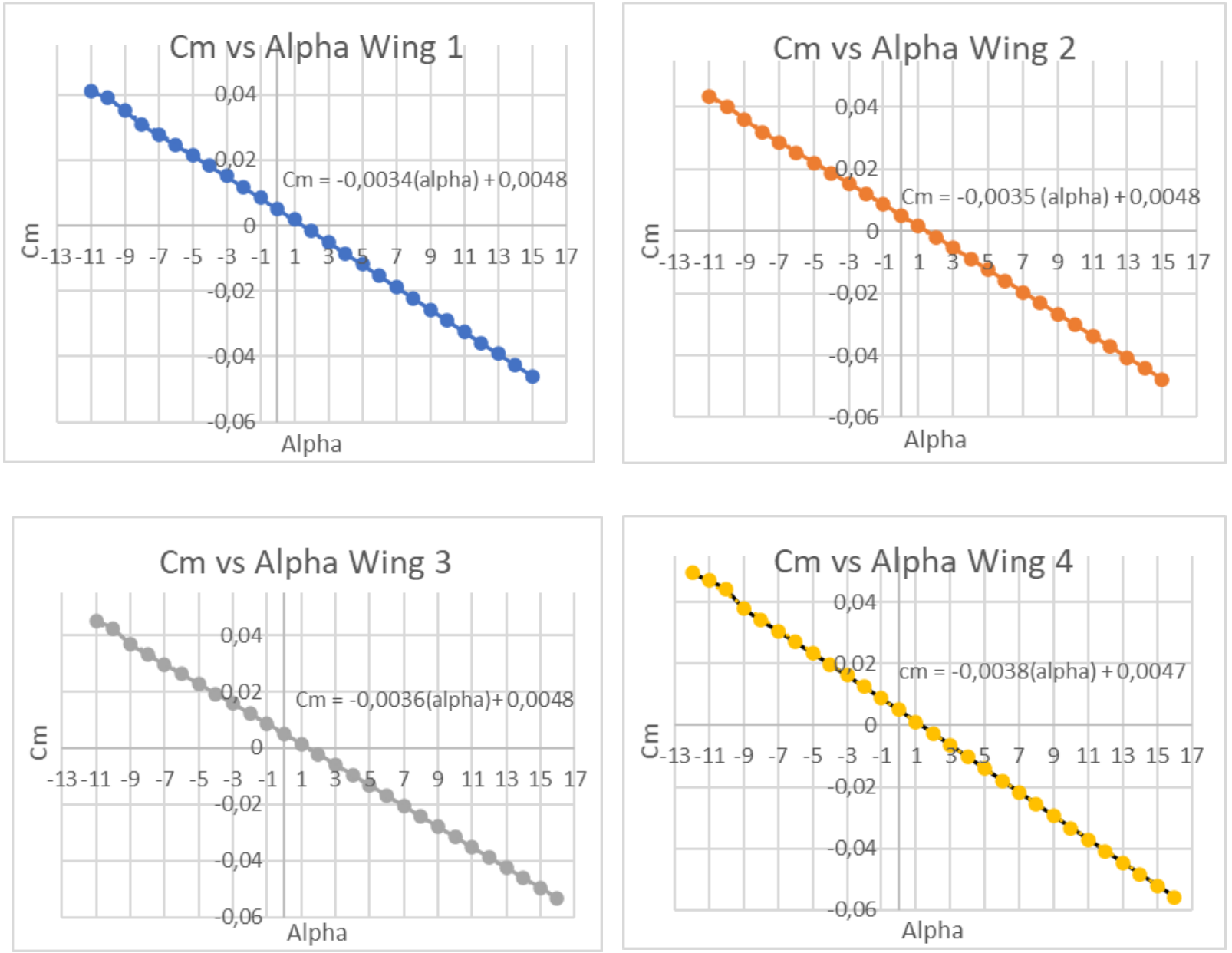

Gambar 7. Regresi $C_{m}$ vs $\alpha$.

Dari Gambar 7 didapatkan regresi $C_{m}$ pada wing 1 adalah $C_{m}=-0,0034 \alpha+0,0048$, wing 2 adalah $C_{m}=-$ $0,0035 \alpha+0,0048$, wing 3 adalah $C_{m}=-0,0036 \alpha+0,0048$, wing 4 adalah $C_{m}=-0,0038 \alpha+0,0047$.

\section{Kesimpulan}

1. Seluruh variasi geometri wing stabil statik longitudinal dikarenakan gradien momen pitch memiliki gradien negatif. $C_{m a}<0$. 
2. Penambahan sudut swept pada sayap pesawat berpengaruh terhadap kestabilan statik longitudinal dimana pada variasi tersebut, tiap penambahan sudut kestabilan pesawat meningkat berdasarkan gradien momen pitch dan regresi yang dihasilkan pada varian wing tersebut.

\section{Daftar Pustaka}

[1] Finn, R. L., Wright, D. (2012). Unmanned aircraft systems: Surveillance, ethics and privacy in civil applications. Computer Law \& Security Review, 28(2), 184-194.

[2] Finke, C., Butts, J., Mills, R., Grimaila, M. (2013). Enhancing the security of aircraft surveillance in the next generation air traffic control system. International Journal of Critical Infrastructure Protection, 6(1), 3-11.

[3] Gularso, H., Rianasari, H., Silalahi, F. E. S. (2015). Penggunaan foto udara format kecil menggunakan wahana udara nir-awak dalam pemetaan skala besar. GEOMATIKA, 21(1), 3744.

[4] Suroso, I. (2018). Analisis Peran Unmanned Aerial Vehicle Jenis Multicopter dalam Meningkatkan Kualitas Dunia Fotografi Udara di Lokasi Jalur Selatan Menuju Calon Bandara Baru di Kulonprogo, REKAM: Jurnal Fotografi, Televisi, Animasi, 14(1), 17-25.

[5] Sandi, D. (2017). Analisis Kestabilan Statik Pesawat Uav Sky King Menggunakan Software Xflr5, Prodi Teknik Penerbangan, STTA. Yogyakarta.

[6] Abdullah, I. F. (2018). Desain dan Pembuatan Panduan Perawatan Pesawat Uav Flying Wing Go-Drone STTA, Departemen Teknik Dirgantara, STTA. Yogyakarta.

[7] Hepperle, M. (2020, November 04). Basic Design of Flying Wing Models. Retrieved from www.mh-aerotools.de: https://www.mh-aerotools.de/airfoils/flywing 1.htm 
Prytha Virgiawan Lesalli, M. Ardi Cahyono 